\title{
DE HERVORMDE KERK IN SURINAME IN HAAR BEGINTIJD
}

\author{
DOOR
}

\section{F. Oudschans Dentz}

In de Encyclopaedie van Ned. West-Indië 1) behandelde H.B. de Hervormde gemeente, waarvan volgens den schrijver gegevens voor een volledige geschiedenis ontbraken. Hetgeen omtrent de eerste levensjaren dezer gemeente en haar verschillende kerkgebouwen wordt medegedeeld, is dan ook zeer mager en bovendien niet geheel juist.

Toch hebben verschillende schrijvers dit onderwerp behandeld, als ds C. van Schaick in West-Indië 2) van 1855, ds C. van Dissel in zijn Eenige bijzonderheden betreffende de Christelijk Hervormde Gemeente te Paramaribo ${ }^{3}$ ), de schrijver dezes in het Protestantenblad van de kolonie 4), Wolbers ${ }^{5}$ ) enz, alle verschenen, voordat de Encyclopaedie in 1917 uitkwam. In een reeks van artikelen in Hervormd Nederland 6) over de Hervormde kerken overzee, besloten wij met no VII De Nederlandsch Hervormde kerk van Paramaribo, waarin wij een samenvatting gaven van hetgeen over deze kerk geschreven is.

Verbetering van een gedeelte van het artikel in de Encyclopaedie van Ned. W.I., is het doel van deze publicatie.

Over de kerk van Thorarica kan het volgende worden medegedeeld.

De ligging van Thorarica of Zandpunt, een weinig beneden de Siparipabo-kreek aan de Surinamerivier nabij ,LLa Simplicité” is behandeld in het artikel: Een niet uitgevoerd evacuatieplan van de hoofdstad van Suriname in de 18de eeuw" 7).

1) Blz. 239/46

2) Blz. $4 / 41$ en $81 / 88$

3) 1877

4) 25 September, 2, 9, en 16 October 1915

s) Blz. 62. 185/6, 192/201, 257, 269/73, 382, 400/1, 495, 559, 670, 677.

6) 21 Mei 1942 en 4 Juni 1942 , nos. 145 en 146.

7) Tijdschrift van het Koninklijk Ned. Aardrijkskundig Genootschap, Maart 1947, no. 2. 
Als predikant stond te Thorarica de Middelburger ds Johan Basseliers, de eerste Nederlandsche predikant in Suriname, die in 1668 met Crijnssens tweede expeditie naar Suriname was medegekomen, tot zijn dood in 1689. Over het zendingswerk is weinig bekend. Het is zeer lang geleden, dat er iets in theologische ${ }^{1}$ ) en andere tijdschriften ${ }^{2}$ ) is gepubliceerd en voor de meesten is dit niet gemakkelijk bereikbaar. Het zijn twee brieven ${ }^{3}$ ) aan de classis te Middelburg geschreven. Ik ontleen daaraan de volgende gegevens, die het leven en den arbeid van ds Basseliers in het licht stellen.

Bij zijn aankomst in Suriname woonden er een 7 a 8-tal Nederlanders. Zij die met hem medegekomen waren om naar Berbice door te reizen, lieten hem wegens zijn zwakke gezondheid in Suriname achter. Hoewel hij te Thorarica stond, hield hij ook godsdienstoefeningen te Paramaribo en bediende des Zondags beide dorpen, die $7 \frac{1}{2} \mathrm{~km}$ van elkaar verwijderd lagen, om beurten, een zware taak voor een niet al te sterken man in die dagen. Het traktement, waarop hij in 1668 was medegekomen, bedroeg $f 800$ tot 1200-, maar, zooals uit een brief van 15 Mei 1685 blijkt 4), had hij in zeven jaar tijds geen traktement ontvangen en was men hem toen $f 8.400$ schuldig. Toch bleef hij op zijn standplaats met opgewektheid en liefde zijn taak vervullen in het onchristelijke land en schreef hij in zijn eersten brief: ,,broeders, bid voor mij, die hier ben als een eensame musch op het dack, opdat, terwijl de duysterheid de volkeren en de donkerheid de natien nog bedekt, Zions puijn en vervallen muuren onder en door mijn swakke dienst alhier mogte herbouwt, het vallende geschoort, het swakke gesterkt worden".

De gemeente bleef klein. Hij schrijft, dat hij onder een volk leeft en woont, ,,dat met geen lust bevangen en word, sig met wind voed en in zijn droefenis blijft sitten sonder te willen geroert of bewogen te worden, schoon de slaande engel 't land doorwandelt heeft, slaande bijna van huis tot huis met pestilentiale coortsen en uytteerende siekten en eijndelijk de dood". Hieruit zou men opmaken, dat Suriname ongezond was s) maar elders

1) Het Tijdschrift voor Gereformeerde Theologie, S. 2. Jrg. I (1894), blz. 324,341 .

2) Stemmen des Tijds, October 1919, no. 12 .

3) Van 16 Januari en 12 September 1676

4) Van Van Aerssen van Sommelsdyck aan de directeuren der Societeyt

s) Willoughby schrijft in 1650 aan zijn vrouw, nadat hij sergeant major A. Rowse naar Suriname gezonden had om een geschikte plaats 
wordt dit duidelijk weersproken. Er was toen echter bijna geen huis waar geen doode was. De predikant zelf klaagt over geheugenzwakte. In zijn woning waren 6 dooden: 2 lieve kinderen, een neger, een Indiaansch kind en nog twee anderen. Hij preekte in een ,oude vervallen kercke, cleijn, rondom open en van boven met gaten, in 't midden van 't bosch staande" Liever ziet men hem ,"' teinden adem en cragten spreken" (bedoeld is dat men hem liever zag ophouden met preken), zoodat hij menigmalen denkt, dat het beter is, binnenkort maar den dienst te verlaten.

Hij schrijft in 1676: ,in acht jaren niet een duijt van mijn gage genoten hebbe", behalve dat zijn zwager 4 maanden geleden na 3 à 4 jaren lang aandringen $f 600$ 1) voor 3 jaren dienst heeft ontvangen en het gouvernement hem nog $£ 1000$ schuldig is, ,slegte belooninge voorwaar voor trouwe en moeylijke diensten".

In 1676 vraagt hij daarom ontslag en een andere standplaats, waar men beter betaalt, anders is hij wel genegen nog een paar jaar te blijven, ,,want een dorschende osse moet men niet muylbanden".

Het is begrijpelijk, dat onze predikant zonder inkomsten verplicht was op een andere wijze aan de kost te komen en plantages aanlegde, die daarin voorzagen. Zo was hij aanlegger en eigenaar van twee plantages, een nabij die van de zusters van gouverneur Van Sommelsdyck, hoog op de rivier, en een andere nabij Thorarica, niet ver van de Joden Savanna, naast de plantage van Van Scherpenhuyzen, „Palmeneribo”. Toen de gouverneur Van Sommelsdyck waterwerken op de plantages deed aanleggen, waren de eerste plantages, waarop zulks geschiedde, die van ds Basseliers en van Van Scherpenhuyzen.

In 1672 zonden de Staten van Zeeland eindelijk een tweede

voor vestiging van een kolonie te zoeken: „It is commended by all that went, for the sweetest place that ever was seen, delicate rivers, brave land, fine timber. They were out almost five months and amongst forty persons, not one of them had so much as their head ache. They all commend the air to be so pure, and the water so good, as they had never such stomachs in their lives, eating, five times a day, plenty of fish and fowl, partridges and pheasants, innumerable, brave savannahs, where you may in coach or on horseback ride thirty or forty mies". Suriname voor de verovering door Abraham Crynssen" door Fred. Oudschans Dentz. Bydragen en Mededeelingen van het Historisch Genootschap. Deel XXXIX (1918), noot 59, Ontleend aan het Sloane MSS 3662 in het Britsch Museum.

1) Dit zal een Vlaams pond zijn geweest, ter waarde van zes gulden. 
predikant, een Franschman van afkomst, ds François Chaillon 1) ,,om duyts te prediken" te Paramaribo, zodat deze Basseliers' taak te Paramaribo kon verlichten. Maar lang bleef Chaillon er niet, en de kerk van Paramaribo bleef vacant en werd opnieuw door Basseliers bediend.

Hoe goed hij aangeschreven stond, is wel hieruit gebleken, dat hij in Juli 1685 ,,met pluraliteyt van stemmen werd genommineert tot Raed deser Provincie om daeruyt door Sijne Excellentie d'Electie gedaen te worden", maar hij nam de benoeming niet aan, aangezien hij beide uiteenloopende functiespredikant en raadsheer - niet naar behoren kon vervullen, Blijkens de politieke notulen van 3 Sept. 1685 verzocht ds Basseliers den gouverneur hem te willen verontschuldigen. Hoewel gouverneur Van Aerssen van Sommelsdyck sterk op de aanvaarding zijner benoeming aandrong, zwichtte hij ten slotte voor het verzoek van den predikant.

In 1687 werd een tweede gereformeerde predikant uitgezonden, ds Heinrich Rosinus, afkomstig uit Koningsbergen, die echter wegens onchristelijken levenswandel werd geschorst. Deze huwde in 1692 met Maria Françoise Brulan de Versan, geb. te St. Omer, weduwe van baron de Corval.

Ds Basseliers overleed in 1689.

Gedurende de jaren 1697-1699 stond de kerk te Thorarica onder ds Bernhart Ter Maath, en na diens overlijden, in Juni 1700, werd zij met de kerk van Paramaribo vereenigd.

Ik heb eenigszins uitvoerig stilgestaan bij deze gemeente, aangezien zij de eerste was in de eerste hoofdstad van Suriname, met een vasten predikant, van wien tot nu toe weinig bekend was.

Alvorens over te gaan tot de kerk van Commewijne verbeter ik een drukfout in de Encyclopaedie waarin als overlijdensjaar van ds Ter Maath staat aangegeven 1799, inplaats van 1699 2). In nagenoeg alle werken over Suriname kan men lezen, dat er in 1688 in de Commewijne, aan de samenvloeiing van de Commewijne en Cottica, dus op Sommelsdijk, een Hervormde kerk werd gebouwd. Ds C. van Schaick schrijft het in West-Indie ${ }^{3}$ ), Wolbers

1) Volgens De Rocheforts Tableau had er vóór 1665 eends Chaillon of Chaillou op Tobago gestaan, en leefde daar ook een Jean Chaillon of Chailiou.

2) Blz. 678 .

3) Proeve van of bijdrage tot de geschiedenis vooral van de Hervormde kerk in Suriname, door C. van Schaick. West-Indië, 1855, deel I, blz. 82. 
neemt het van dezen over 1), de Encyclopaedie van Ned. W.I. ${ }^{2}$ ) meldt het in navolging. Zoowel jaartal als plaats zijn echter fout. De kerk in de Commewijne moet gebouwd zijn vóór 1682. Deze mededeling danken wij aan de predikant ds. J.W. C. Ort, destijds te Paramaribo, die daarop in 1920 onze aandacht vestigde.

Waarop zij gegrond is, zal uit het volgende blijken. In de niet volledige lijst van predikanten van de Hervormde kerk (waarin trouwens onjuistheden voorkomen), opgenomen in de Surinaamsche Almanak voor het jaar $\left.1830{ }^{3}\right)$, in West-Indië 4), en bij Wolbers $\left.{ }^{5}\right)$ staat niet vermeld ds Adriaan Backer, die gestaan heeft in de kerk van Calis in de Commewijne. Calis ligt aan de monding van de Cassewinica, tegenover de Bottelkreek. Men kan dezen ouden naam nog terugvinden op de oude kaart van Moseberg en bij Stedman en - volgens ds Ort - in de oudste Surinaamsche Almanak. Deze plaats was door de oude kolonisten uitmuntend gekozen voor een kerk en in het algemeen voor een plaats van samenkomst (rendez-vous in tijd van nood), daar ze over de rivieren gemakkelijk bereikt kon worden. $\mathrm{Zij}$ is een centrum en ligt ongeveer in het midden van de rivier. De Boven-divisie van Commewijne ligt opwaarts van Calis, de Beneden-divisie beneden deze plaats. De kerk was gebouwd voor de toenmalige bewoners van Commewijne en Cottica. In 1688 waren die er niet in de omgeving van Sommelsdijk, zoals de oude kaarten aantonen. De Beneden-Commewijne was beneden de samenvloeiing onbewoond, evenzo de Cottica boven de samenvloeiing tot een heel eind hoger op dan de uitmonding van de Perica.

In de Commewijne, hoger dan de schans Sommelsdijk, begonnen de plantages aan den linkeroever bij de Commetewane en bij de monding van de Kruiskreek rechts. Aangezien de kerk te water en met het getij moest bereikt worden, zou de plaatsing op Sommelsdijk uiterst onpractisch zijn geweest. Zo iets zouden onze voorouders niet gedaan hebben. De eenige gunstige ligging voor een kerkgebouw in het district was in een centrum en dat lag voor de Commewijne veel hoger op. In de Cottica waren te weinig bewoners om voor een kerk in aanmerking te komen. Hoewel Hartsinck alle kerken opnoemt, gewaagt hij — ten rechte

1) Blz. 62 .

2) Blz. 358 .

3) Blz. 239/246.

4) Deel I, blz. $19 / 22$

s) Blz. $846 / 7$. 
- niet van die van Sommelsdijk. Wel noemt hij een kerk in de Bovenverdeling (Boven-divisie) van de Commewijne.

De mogelijkheid bestaat, dat latere schrijvers hebben gedacht, dat met Boven-divisie fort Sommelsdijk werd bedoeld en zo zou dan de legende van een kerk daar ter plaatse kunnen zijn ontstaan.

Ds Backer - over wien ik reeds sprak - werd in 1682 overgeplaatst en vertrok naar Paramaribo, waar geen predikant was. Den 27sten Februari werd volgens de politieke notulen besloten, ,den Hr Adriaan Backer, Predikant dezer Provincie” te verzoeken zijn dienst als predikant in de kolonie voort te zetten en zich metterwoon te Paramaribo te vestigen, met een traktement van $f 1200$ - dat stipt per kwartaal zou worden betaald. Bovendien kreeg hij vrij wonen in de pastorie.

Op 15 April leest men in de notulen, dat ds Backer gereed staat uit de Commewijne naar Paramaribo te komen om aldaar het predikambt te bedienen. Een huis, water- en winddicht, wordt voor hem ingeruimd; voor onderhoud daarvan wordt het eerste jaar $f 100$ - toegezegd, het tweede jaar $f 75-$ enz.

Een jaar later leest men in de notulen, op 12 Februari 1683, dat ds Backer geklaagd heeft dat de betaling van zijn traktement te wensen overlaat, dat hem dit al meer was overkomen en dat hij geen staat kon maken op de beloften van den Politieken Raad. Dus al net als bij ds Basseliers. Hem wordt geantwoord dat commandeur en raden nauwgezet zullen zorgen voor uitbetaling van zijn gage per kwartaal uit de eerst inkomende middelen, doch dat niemand van de Heeren raden zich in privé wilde verbinden voor de prompte uitbetaling. Was ds Backer hiermede niet tevreden, dan werd hem toegestaan - hoewel tot leedwezen der regeering - gebruik te maken van het middel hem vroeger reeds op een request in margine aangeduid. Hij nam dus ontslag en in Maart 1683 wordt hem een attestatie gegeven naar Nederland te repatrieeren. Daarin wordt vermeld, dat ,,de Hr. Adriaan Backer zich in zijn bediening trouw betoond heeft, en dat hij in 't bijzonder tijdens den droevigen binnenlandschen oorlog tegen de Indianen en de ongelukkige oeconomische omstandigheden van die dagen de inwoners heeft gesticht door leer en leven".

De gemeente te Calis bleef vacant tot 1687, toen ds Keetelaar kwam, die voor de Commewijne was aangewezen. In dien tusschentijd schijnt ds Basseliers van tijd tot tijd daar gepreekt te hebben, althans wij zien, dat hij de dienst Zondag 19 Mei 1686 waarnam. 
Hiermede nemen wij afscheid van ds Backer.

Het verdere verloop van de kerk van Calis is de volgende. In 1699 werd den landmeter Bogaert opgedragen te onderzoeken hoe groot de hoek van Calis was en aan wien deze toebehoorde. De directeur van de plantage ,Rosenbeek” was nl. bezig daar bos te vellen en de grond te beplanten. Blijkens de politieke notulen van 3 Juli 1699 verklaart Bogaert, dat het land of de hoek van Calis, groot 24 akkers, altijd is beschouwd als een openbaar terrein, waar in vroeger tijden de kerk van beide divisiën van de Commewijne heeft gestaan, omdat de plaats in het midden der rivier gelegen is.

In de Commewijne hebben dus eertijds twee kerken gestaan, een in de Beneden- en een in de Boven-divisie. De Benedendivisie strekte zich toen uit van de Cassawinica tot de schans Sommelsdijk. Den 5den Januari 1697 klagen de ingezetenen van de Commewijne over de moeilijkheden, die zij ondervinden bij het brengen van den toenmaligen predikant Wachtendorp van zijn woning naar de kerken. De planters in Commetewane zijn met halen en brengen, als zij daarvoor de beurt hebben, acht dagen kwijt! Daarop besluiten gouverneur en raden, dat de predikanten, wanneer zij beide divisiën waarnemen (dus in beide kerken den predikdienst hebben te verrichten) bij een der kerken moeten wonen, ,,gelijk ds Keetelaar Zalr heeft gedaan”.

Waar stond toen de kerk van Beneden Commewijne?

Uit de notulen van 12 Januari 1702 blijkt, dat in de Benedendivisie een geschikt huis nodig is om de godsdienstoefeningen te kunnen houden, en besloten wordt bij de plaats, waar de vorige kerk heeft gestaan, een nieuw huis te bouwen, 50 voet lang, 30 voet breed van goed bolletreehout, rondom met planken belegd en met singels bedekt. Een jaar later - 19 Januari 1703 als de zaak weer aan de orde komt, wordt besloten voortgang te maken met het huis ,,aan Courcabo".

Te Courcabo werd in 1703 tegenover Potribo een tweede gereformeerde kerk gebouwd. Hartsinck spreekt van de ,kerk naast de plantage Curcabo" 2).

Wat de Boven-divisie van Commewijne betreft, leest men, dat gouverneur en raden op 12 Maart 1691 bespreken, dat de kerk in de oplandsche divisie in zulk een slechten staat verkeert, dat zij noodzakelijk moet worden neergehaald en er wordt besloten, in plaats van de oude vervallen kerk een nieuwe te bouwen naar het model van die van Perica.

1) Hartsinck, blz. 577 . 
Op 1 October 1702 wordt evenwel verzocht de kerk, tegenwoordig staande in de Boven-divisie te plaatsen op Calis. Terwijl dus sommigen de kerk weder benedenwaarts wensen te verplaatsen, blijkt het in dit geval, dat in genoemd jaar 1702 de kerk van de Boven-divisie niet op Calis stond, zoals reeds uit het rapport van den landmeter Bogaert is te lezen.

De kerk van Boven-Commewijne stond op een stuk grond, door den heer Jan de Backer - die zelf kerkmeester was - daartoe afgestaan, een deel van zijn plantage 1). Lang na zijn dood rezen er moeilijkheden over deze kerkgrond met een nieuwe eigenaresse van de plantage. In 1721 rapporteert de commissie voor woning en kerk in de Boven-Commewijne, dat de kerkmeester bekend heeft gemaakt, dat de weduwe Guigeur hem had verklaard onder voorgeven, dat de kerk op haar land stond, niet te zullen dulden, dat aldaar enige woningen werden gebouwd, zoals steeds bij alle kerken is geschied, althans tot logies van de predikant.

Er wordt in de raad besloten ter secretarie na te zien, op welke voorwaarden Jan de Backer vergund heeft de kerk op diens grond te plaatsen en, wanneer de weduwe Guigeur blijft weigeren, zal getracht worden haar te overreden enige kettingen land af te staan voor het bouwen van huizen, waarin kerkbezoekers tijdelijk kunnen verblijven, zoals ook in andere divisies bij de kerken het geval is.

Samenvattende de positie der kerk in Commewijne, blijkt:

1. dat er geen kerk op Sommelsdijk heeft bestaan;

2. dat de kerk in Commewijne niet in 1688 kan zijn gebouwd, maar reeds in 1682 stond te Calis, bediend door ds. Backer;

3. dat voor het gemak der toenemende bevolking de gemeente in tweeën werd gesplitst; de Beneden-divisie met een vergaderlokaal te Courcabo, de Boven-divisie met een huis voor godsdienstoefeningen op de plantage van Jan de Backer. Ds Keetelaar bediende beide gemeenten; in zijn tijd bestond misschien nog de kerk op Calis en woonde hij daarbij.

Daarna had elke divisie een eigen predikant: ds Moraeus op Courcabo, ds Wachtendorp in de Boven-divisie. Na Moraeus dood bediende ds Wachtendorp weer beide gemeenten;

1) No. 69 op de kaart van 1688, behorende bij het artikel: „,De Labadisten in Suriname", door L. Knappert, De West-Indische Gids, 1926 8ste jrg. blz. 193. 
DE HERVORMDE KERK IN SURINAME IN HAAR BEGINTIJD 361

4. dat men later op het denkbeeld kwam de kerk van de Bovendivisie naar de oude plaats Calis te verleggen;

5. dat bij het terugtrekken der bevolking uit Boven-Commewijne daar geen kerk meer nodig was. Maar de kerk op Courcabo bleef lang bestaan. Althans Hartsinck gewaagt er nog van in 1770. Dat was toen in de Boven divisie, maar in de oudere tijd tijdelijk Beneden-divisie;

6. dat aan het eind van de 18de eeuw de gedachte opkwam, de kerk van Courcabo te verplaatsen naar Sommelsdijk, maar daarvan niets is gekomen. 